\title{
Naringenin induces laxative effects by upregulating the expression levels of c-Kit and SCF, as well as those of aquaporin 3 in mice with loperamide-induced constipation
}

\author{
JIANQIAO YIN, YICHAO LIANG, DALU WANG, ZHAOPENG YAN, HONGZHUAN YIN, DI WU and QI SU \\ Department of General Surgery, Shengjing Hospital of China Medical University, Shenyang, Liaoning 110004, P.R. China
}

Received March 22, 2016; Accepted September 13, 2017

DOI: $10.3892 /$ ijmm.2017.3301

\begin{abstract}
Constipation is a common affliction which causes discomfort and affects the quality of life of affected individuals. Naringenin (NAR), a natural flavonoid widely found in citrus fruits and tomatoes, has been reported to exhibit various pharmacological effects, such as anti-inflammatory, antiatherogenic, anti-mutagenic, hepatoprotective and anticancer effects. Increasing evidence has indicated that NAR has potential for use in the treatment of constipation. Thus, the aim of this study was to evaluate the laxative effects of NAR in mice with loperamide-induced (Lop-induced) constipation. The data indicated that NAR relieved Lop-induced constipation in mice based on the changes of fecal parameters (numbers, weight and water content), the intestinal charcoal transit ratio and the histological alteration. ELISA revealed that NAR regulated the production levels of gastrointestinal metabolic components, such as motilin (MTL), gastrin (Gas), endothelin (ET), substance P (SP), acetylcholinesterase (AChE) and vasoactive intestinal peptide (VIP) in serum. The expression levels of enteric nerve-related factors, glial cell line-derived neurotrophic factor (GDNF), transient receptor potential vanilloid 1 (TRPV1), nitric oxide synthase (NOS), c-Kit, stem cell factor (SCF) and aquaporin 3 (AQP3) were examined by western blot analysis and RT-PCR analysis. The results of this study suggest that NAR relieves Lop-induced constipation by increasing the levels of interstitial cells of Cajal markers (c-Kit and SCF), as well as AQP3. Thus, NAR may be effective as a candidate in patients suffering from lifestyle-induced constipation.
\end{abstract}

\section{Introduction}

Constipation is one of the most frequent health afflications which causes discomfort and affects quality of life of patients (1). A relatively large number of subjects in the general

Correspondence to: Dr Qi Su, Department of General Surgery, Shengjing Hospital of China Medical University, 36 Sanhao Street, Shenyang, Liaoning 110004, P.R. China

E-mail: suqi20151204@sina.com

Key words: constipation, naringenin, loperamide, interstitial cells of Cajal, aquaporin 3 population (ranging from approximately $9 \%$ to more than $20 \%$, depending on the geographical area) is affected by this highly prevalent functional gastrointestinal disorder (2). It is a complex symptom and increases during aging. Constipation can cause not only discomfort, but also restlessness, abdominal distension, vomiting, gut obstruction and perforation, and even aspiration or fatal pulmonary embolism (3). Slow-transit constipation (STC) is the most common type of chronic constipation (4), which is a motility disorder characterized by markedly increased total bowel transit time (5). The pathogenesis of constipation remains largely unknown. Earlier investigations have focused on the quantitative alternations of the interstitial cells of Cajal (ICCs), the pacemaker of the gastrointestinal tract. The complete absence or a significant reduction in the number of ICCs in colon specimens resected from patients with STC has been reporeted in comparison with normal controls (6). In addition, a number of other pathophysiological abnormalities, including the degeneration of the myenteric plexus ganglia, the aberrant expression of smoothelin protein, and abnormalities of the enteric neurotransmitters may be associated with constipation $(7,8)$. However, the mechanisms through which these numerous abnormalities contribute to the pathogenesis of constipation remain to be further elucidated.

Naringenin (NAR), a natural flavonoid widely found in citrus fruits and tomatoes, has been reported to exhibit various pharmacological effects, such as anti-inflammatory, antiatherogenic, anti-mutagenic, hepatoprotective and anticancer effects $(9,10)$. There is increasing evidence to indicate that NAR has potential for use in the treatment of constipation. Yang et al reported that NAR stimulated $\mathrm{Cl}^{-}$secretion in the colonic epithelium via a signaling pathway involving cyclic adenosine monophosphate (cAMP) and protein kinase A (PKA) (11). However, the precise effects of NAR on constipation have not been investigated thus far, at least to the best of our knowledge.

In this study, we examined the effect of NAR on loperamide (Lop)-induced constipation in rats, indicating its therapeutic potential for the treatment of constipation and other related diseases.

\section{Materials and methods}

Ethics statement. This study was performed in strict accordance with the recommendations of the Guide for the Care and Use of Laboratory Animals of the National Institutes of 
Health. The animal protocol used in this study was reviewed and approved by the Institutional Animal Care and Use Committee (IACUC) according to the National Institutes of Health Guidelines (permit no. A27-011-0). Mice were anaesthetized with $50 \mathrm{mg} / \mathrm{kg}$ pentobarbital sodium during the necessary operations, and every effort was made to minimize suffering.

Experimental animals. Adult ICR mice were purchased from Charles River Ltd. (Beijing, China). All mice were provided with standard irradiated chow diet ad libitum and maintained in a specific pathogen-free state under a strict light cycle (12/12-h) at a temperature of $22 \pm 2^{\circ} \mathrm{C}$ and a relative humidity of $50 \pm 10 \%$.

Induction of constipation and experimental design. Constipation was induced in ICR male mice (8 weeks old, 18-22 g) by the intragastric administration of Lop (Xi'an Janssen Pharmaceutical Co., Ltd., Shanxi, China) (3 mg/kg weight) in sterilized physiological saline once a day for 5 days, whereas the non-constipation group was administered sterilized physiological saline alone. For the animal experiment, the ICR mice were assigned to either a non-constipation group (negative control group) or a constipation group.

For the experiment, the ICR mice were divided into the following groups: i) the negative control group (No group, $\mathrm{n}=6$ ) in which mice were treated with a consistent volume of sterilized physiological saline; ii) the Lop + Vehicle group $(n=6)$ in which mice were treated with Lop and the vehicle at the same volume as the NAR-treated groups; iii) different NAR-treated groups including the Lop + NAR75 $(n=6)$, Lop + NAR150 $(n=6)$ and Lop + NAR300 (n=6) groups, in which mice first were treated with Lop and $1 \mathrm{~h}$ later treatment with 75, 150 and $300 \mathrm{mg} / \mathrm{kg}$ body weight of NAR (Dalian Meilun Biotech Co., Ltd., Dalian, China) once a day for 5 days. The Lop + Vehicle group also received a consistent volume of sterilized physiological saline via gavage following treatment with Lop. At 5 days after NAR treatment, all animals were sacrificed and tissue samples were acquired and stored in Eppendorf tubes at $-70^{\circ} \mathrm{C}$ until assay.

Measurement of fecal pellet parameters and body weight. The excreted fecal pellets of individual mice were collected at day 6 after the induction of constipation for 5 days. The total number, weight and water content of the pellets were determined. The water content was calculated as the difference between the wet and dry weights of the pellet. Stool and body weight was weighed 3 times per sample using an electric balance.

Measurement of intestinal charcoal transit ratio. The animals were fasted prior to the experiment, but consumed water ad libitum. At day 6 after the induction of constipation for 5 days, the animals were fed charcoal meal (1 mg/100 kg weight) (5\% suspension of activated charcoal in $10 \%$ gum arabic; Sigma-Aldrich, St. Louis, MO, USA). At 30 min after the charcoal meal administration, the animals were first sacrified by cervical dislocation and the abdominal cavity was then opened. The intestines were removed and the total intestine length (from pyloric sphincter to cecum) and charcoal meal transit distance were measured. The intestinal charcoal transit ratio was calculated as follows: charcoal
Table I. The primer sequences used in this study.

\begin{tabular}{ll}
\hline Genes & \multicolumn{1}{c}{ Primer sequences } \\
\hline NOS & F: 5'-TCAGCGGTGATAGGATAAAGCA-3' \\
& R: 5'-CGCTGTGCTAAGTAGCCCTCG-3'-3'' \\
TRPV1 & F: 5'-TCTCGTGGAGCCCTTGAACCG-3' \\
& R: 5'-CCGATAGTAAGCAGCCGTGGT-3' \\
GDNF & F: 5'-GACGCTTGGTGGTTGATTCTG-3' \\
& R: 5'-GTTTCTGAGGGCACGAAGGAG-3' \\
BDNF & F: 5'-CAATCGCTTCATCTTAGGAGT-3' \\
& R: 5'-TAAACGGCACAAAACAATC-3' \\
c-Kit & F: 5'-CCGACGCAACTTCCTTATGAT-3' \\
& R: 5'-TCAGGACCTTCAGTTCCGACA-3' \\
SCF & F: 5'-ATAGTGGATGACCTCGTGTTA-3' \\
& R: 5'-GAATCTTTCTCGGGACCTAAT-3' \\
AQP3 & F: 5'-GCCAAGGTAGGATAGCAAATAA-3' \\
& R: 5'-TTGAAAACTTGGTCCCTTGC-3' \\
& F: 5'-CTGTGCCCATCTACGAGGGCTAT-3' \\
& R: 5'-TTTGATGTCACGCACGATTTCC-3'
\end{tabular}

F, forward; R, reverse; NOS, nitric oxide synthase; TRPV1, transient receptor potential cation channel subfamily V member 1; GDNF, glial cell line-derived neurotrophic factor; BDNF, brain-derived neurotrophic factor; SCF, stem cell factor; AQP3, aquaporin 3.

transit ratio $(\%)=($ distance travelled by the charocal $) /($ total length of small intestine) $\times 100 \%$.

Histological analysis. The proximal colons collected from the ICR mice were fixed with $4 \%$ paraformaldehyde (Sinopharm Group Co., Ltd., Shanghai, China) for $30 \mathrm{~min}$, embedded in paraffin wax, and then sectioned into $5-\mu \mathrm{m}$-thick slices that were stained with H\&E (Hematoxylin, Solarbio Co., Ltd., Beijing, China; Eosin, Sinopharm Group Co., Ltd.). Morphological features of these sections were observed under a light microscope (DP73; Olympus, Tokyo, Japan).

Real-time PCR. The proximal colons were chopped with scissors and total RNA was extracted using a high-purity total RNA extraction kit (RP1201; BioTeke Co., Ltd., Beijing, China) according to the manufacturer's instructions. Gene expression was then examined by RT-PCR using total RNA from each tissue. The complementary DNA (cDNA) was synthesized from total RNA using a Super M-MLV reverse transcriptase kit (PR6502; BioTeke Co., Ltd.). The reverse transcription products were then amplified for PCR. Primers used in RT-PCR are listed in Table I. Forward primer, reverse primer and template cDNA were prepared; the reaction conditions for reverse transcriptoin were as follows: $25^{\circ} \mathrm{C}$ for $10 \mathrm{~min}, 42^{\circ} \mathrm{C}$ for $50 \mathrm{~min}$ and $95^{\circ} \mathrm{C}$ for $5 \mathrm{~min}$. The PCR amplification conditions were: $95^{\circ} \mathrm{C}$ for $10 \mathrm{~min}, 40$ cycles of $95^{\circ} \mathrm{C}$ for $10 \mathrm{sec}, 60^{\circ} \mathrm{C}$ for $20 \mathrm{sec}$ and $72^{\circ} \mathrm{C}$ for $30 \mathrm{sec}$, then $4^{\circ} \mathrm{C}$ for $5 \mathrm{~min}$. The PCR results were verified by varying the number of PCR cycles for each cDNA and set of primers. PCR reaction was performed using Exicycler ${ }^{\mathrm{TM}} 96$ (Bioneer Co., Daejeon, Korea) with $\beta$-actin as a control. RT-PCR was performed at least in quadruplicate. 
ELISA. At day 6 after the induction of constipation for 5 days, the serum was obtained from the eyeball before sacrifice under anesthesia by intraperitoneal injection with $50 \mathrm{mg} / \mathrm{kg}$ pentobarbital sodium. The serum from the eyeball of constipated mice treated with or without NAR was harvested and washed in cold phosphate-buffered saline (PBS) twice. The concentrations of gastrin (Gas), endothelin (ET), acetylcholinesterase (AChE), substance $\mathrm{P}$ (SP) and vasoactive intestinal peptide (VIP) in the serum from ICR mice were determined using corresponding detection kits (USNC Life Science Inc., Wuhan, China), according to the manufacturer's instructions. The concentration level of motilin (MTL) in serum was determined using a Mice Motilin ELISA kit (Shanghai Yanjing Biological Technology Co., Ltd., Shanghai, China). The sensitivity of this assay, or the lower limit of detection was defined as the lowest protein concentration that could be differentiated from zero. The minimum detectable doses of Gas, ET, AChE, SP, VIP and MTL are typically less than 4.77, 2.54, 0.28, 4.88, 2.61 and $9.27 \mathrm{ng} / \mathrm{ml}$ in this study, respectively.

Western blot analysis. Proteins collected from the proximal colons of constipated mice treated with or without NAR were lysed in ice-cold radioimmunoprecipitation (RIPA) buffer plus PMSF and protein concentrations in the supernatant were determined using the BCA Protein Assay kit (all agents from Beyotime Institute of Biotechnology Co., Shanghai, China) following the manufacturer's instructions. Total proteins were separated by 8,12 and $14 \%$ sodium dodecyl sulfate-polyacrylamide gel electrophoresis (SDS-PAGE) for $2.5 \mathrm{~h}$, after which the resolved proteins were transferred onto polyvinylidene fluoride membranes (Millipore, Bedford, MA, USA) for $1.5 \mathrm{~h}$ at $80 \mathrm{~V}$. Each membrane was then incubated separately with the primary antibodies, anti-transient receptor potential cation channel subfamily V member 1 (TRPV1; BA2589), antiglial cell line-derived neurotrophic factor (GDNF; BA0890), anti-brain-derived neurotrophic factor (BDNF; BA0565-2), anti-nitric oxide synthase (NOS; BA0360) (1:400; Wuhan Boster Bio-Engineering Co., Ltd., Wuhan, China); anti-c-Kit (bs-0672R), anti-stem cell factor (SCF; bs-0545R) (1:500; Bioss, Beijing, China); anti-aquaporin 3 (AQP3; D260100) (1:500; Sangon Biotech Co., Ltd., Shanghai, China) or anti- $\beta$-actin (1:1,000; sc-47778; Santa Cruz Biotechnology, Inc., Dallas, Texas, USA) overnight at $4^{\circ} \mathrm{C}$. The membranes were then washed with TBS-T buffer (10 mM Tris-HCl, $150 \mathrm{mM}$ $\mathrm{NaCl}$ and $1 \%$ Tween-20) for $30 \mathrm{~min}$ and incubated with horseradish peroxidase-conjugated goat anti-rabbit IgG (Beyotime Institute of Biotechnology Co.) at a dilution of 1:5,000 at room temperature for $1 \mathrm{~h}$. Finally, the membrane blots were developed with an enhanced chemiluminescence detection kit ECL detection reagent (7Sea Biotech, Shanghai, China) according to the manufacturer's instructions. Quantitative analysis for western blot analysis was made by Gel-Pro Analyzer software (Media Cybernetics, Inc., Rockville, MD, USA).

Immunohistochemistry. Paraffin-embedded tissue sections of $5 \mu \mathrm{m}$ thickness were rehydrated first in xylene and then in graded ethanol solutions. The slides were then blocked with $5 \%$ goat serum for $15 \mathrm{~min}$. The sections were then immunostained with primary antibody anti-AQP3 (1:50; D260100; Sangon Biotech Co., Ltd.) and incubated overnight at $4^{\circ} \mathrm{C}$. After washing the slides with PBS 3 times, the sections were incubated with secondary antibody (biotin-conjugated goat anti-rabbit IgG; A0277; Beyotime Institute of Biotechnology Co.) at room temperature for $30 \mathrm{~min}$. Sections were then washed with PBS and incubated for 5-10 min in DAB Horseradish Peroxidase Color Development kit $(0.02 \%$ diaminobenzidine (DAB) containing $0.01 \%$ hydrogen peroxide; Beyotime Institute of Biotechnology Co.). Counter staining was performed using hematoxylin (Solarbio Co., Ltd.) and the slides were visualized under a light microscope (Olympus); all images were taken at x400 magnification.

Statistical analysis. Data are presented as the means \pm standard deviation (SD) from at least 3 experiments. Statistical comparisons were analyzed by Bonferroni's multiple comparison tests or analysis of variance (ANOVA). A value of $\mathrm{P}<0.05$ was considered to indicate a statistically significant difference.

\section{Results}

Body weight and fecal pellet parameters. Constipation was assessed principally by fecal pellet number, weight and water contents to determine the effects of NAR on Lop-induced constipation. Although the body weight in the No group was slightly higher than that of the other groups, there was no significant differences in body weight among all the experimental groups (No group, 20.33 $\pm 1.21 \mathrm{~g}$; Lop + Vehicle group, $19.50 \pm 1.38 \mathrm{~g} ;$ Lop + NAR75 group, $19.67 \pm 1.75 \mathrm{~g}$; Lop + NAR150 group, 19.83 \pm 1.47 g; Lop + NAR300 group, $19.33 \pm 1.37 \mathrm{~g}$; Fig. 1A). Moreover the effects of any treatment on constipation are generally determined based on altered excretion from ICR mice.

To investigate the laxative effects of NAR on stool excretion, alterations in fecal pellet parameters were measured in all groups of mice. The data indciated that the numbers of fecal pellets were significantly reduced by more than half following the administration of Lop when compared with the No group, whereas they were increased by 3.99, 71.99 and $135.98 \%$ in the Lop + NAR75, Lop + NAR150 and Lop + NAR300 groups, respectively, as compared with the Lop + vehicle group $(\mathrm{P}<0.05$; Fig. 1B). Indeed, the weight of stool was reduced approximately half of the No group in the Lop + Vehicle group. However, following treatment with NAR, this level was elevated significantly to that of the No group $(\mathrm{P}<0.05$; Fig. $1 \mathrm{C})$. The total water content of the fecal pellets collected over $24 \mathrm{~h}$ after 6 days decreased by almost $50 \%$ in the Lop + Vehicle group when compared with the No group, and increased by 14.57 , 67.43 and $102.69 \%$ in Lop + NAR75, Lop + NAR150 and Lop + NAR300 groups, respectively, as compared with the Lop + Vehicle group $(\mathrm{P}<0.05$; Fig. 1D). These results suggest that NAR treatment relieves Lop-induced constipation in ICR mice through the enhancement of stool excretion.

Effects on intestinal charcoal transit. A statistically significant decrease in the intestinal charcoal transit ratio was detected in the Lop + Vehicle group when compared with the No group (from $62.67 \pm 6.13 \%$ to $35.44 \pm 11.78 \%$ ). By contrast, statistically significant increases in the intestinal charcoal transit ratio were detected after 6 days of continuous treatment with various concentrations of NAR when compared with the 
A




D



Figure 1. Body weight and fecal parameters following intragastric administration with or without NAR in mice with Lop-induced constipation. (A) Body weight, (B) fecal number, (C) fecal weight and (D) water contents were measured at the same time during the experiment. Six mice per group were assayed in triplicate for body weight and fecal parameters analysis. Data represent the means \pm SD from 3 replicates. ${ }^{* *} \mathrm{P}<0.01$ compared to the No group; ${ }^{\#} \mathrm{P}<0.05$ and ${ }^{\# \#} \mathrm{P}<0.01$ compared to Lop + Vehicle group. Lop, loperamide; NAR, naringenin. The mouse groups were as follows: No, negative control, mice treated with saline; Lop + Vehicle, mice treated with Lop and the vehicle; Lop + NAR75, mice treated with Lop and NAR at $75 \mathrm{mg} / \mathrm{kg}$ body weight; Lop + NAR150, mice treated with Lop and NAR at $150 \mathrm{mg} / \mathrm{kg}$ body weight; Lop + NAR300, mice treated with Lop and NAR at $300 \mathrm{mg} / \mathrm{kg}$ body weight.

Lop + Vehicle group (Fig. 2). The intestinal charcoal transit ratio increased from $35.44 \pm 11.78 \%$ in the Lop + Vehicle group to $43.25 \pm 8.61,53.69 \pm 7.11$ and $57.95 \pm 8.00 \%$ in the Lop + NAR75, Lop + NAR150 and Lop + NAR300 groups, respectively $(\mathrm{P}<0.01$; Fig. 2$)$.

Parameters of serum. To evaluate the effects of NAR on serum biochemical components in the constipated mice, alterations of several components related to gastrointestinal metabolics in serum of the Lop and/or NAR-treated mice were assessed by ELISA. As shown in Fig. 3, serum parameters such as MTL, Gas, ET, AChE, SP and VIP were significantly decreased in the Lop + Vehicle group compared with the No group. However, these parameters, in particular Gas, SP and AChE were increased following treatment with NAR in a dose-dependent manner as compared with the Lop + Vehicle group $(\mathrm{P}<0.05$; Fig. 3$)$. Therefore, these results suggest that NAR treatment may increase the factors related to gastrointestinal movement to relieve Lop-induced constipation in ICR mice.

Histological alterations and the expression levels of enteric nerves-related factors in the colons of mice with Lop-induced constipation. As $300 \mathrm{mg} / \mathrm{kg}$ NAR exhibited the most potent laxative effects in mice with Lop-induced constipation, the mice in the Lop + NAR300 group were used to analyze the

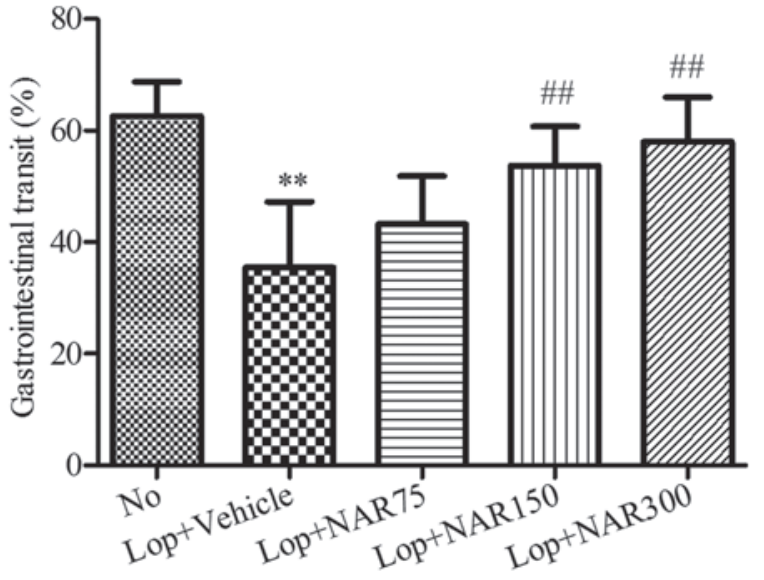

Figure 2. Effects of NAR on GI transit in mice with Lop-induced constipation. Consitipation was induced by the intragastric administration of Lop followed by treatment with or without NAR. The length of charcoal from stomach in the intestine was measured after the administration of charcoal. Charcoal transit ratio $(\%)=($ distance travelled by the charocal $) /($ total length of small intestine) $\times 100 \%$. ${ }^{* *} \mathrm{P}<0.01$ compared to the No group; ${ }^{\# \#} \mathrm{P}<0.01 \mathrm{com}-$ pared to Lop + Vehicle group. NAR, naringenin; GI, gastrointestinal; Lop, loperamide. The mouse groups were as follows: No, negative control, mice treated with saline; Lop + Vehicle, mice treated with Lop and the vehicle; Lop + NAR75, mice treated with Lop and NAR at $75 \mathrm{mg} / \mathrm{kg}$ body weight; Lop + NAR150, mice treated with Lop and NAR at $150 \mathrm{mg} / \mathrm{kg}$ body weight; Lop + NAR300, mice treated with Lop and NAR at $300 \mathrm{mg} / \mathrm{kg}$ body weight. 

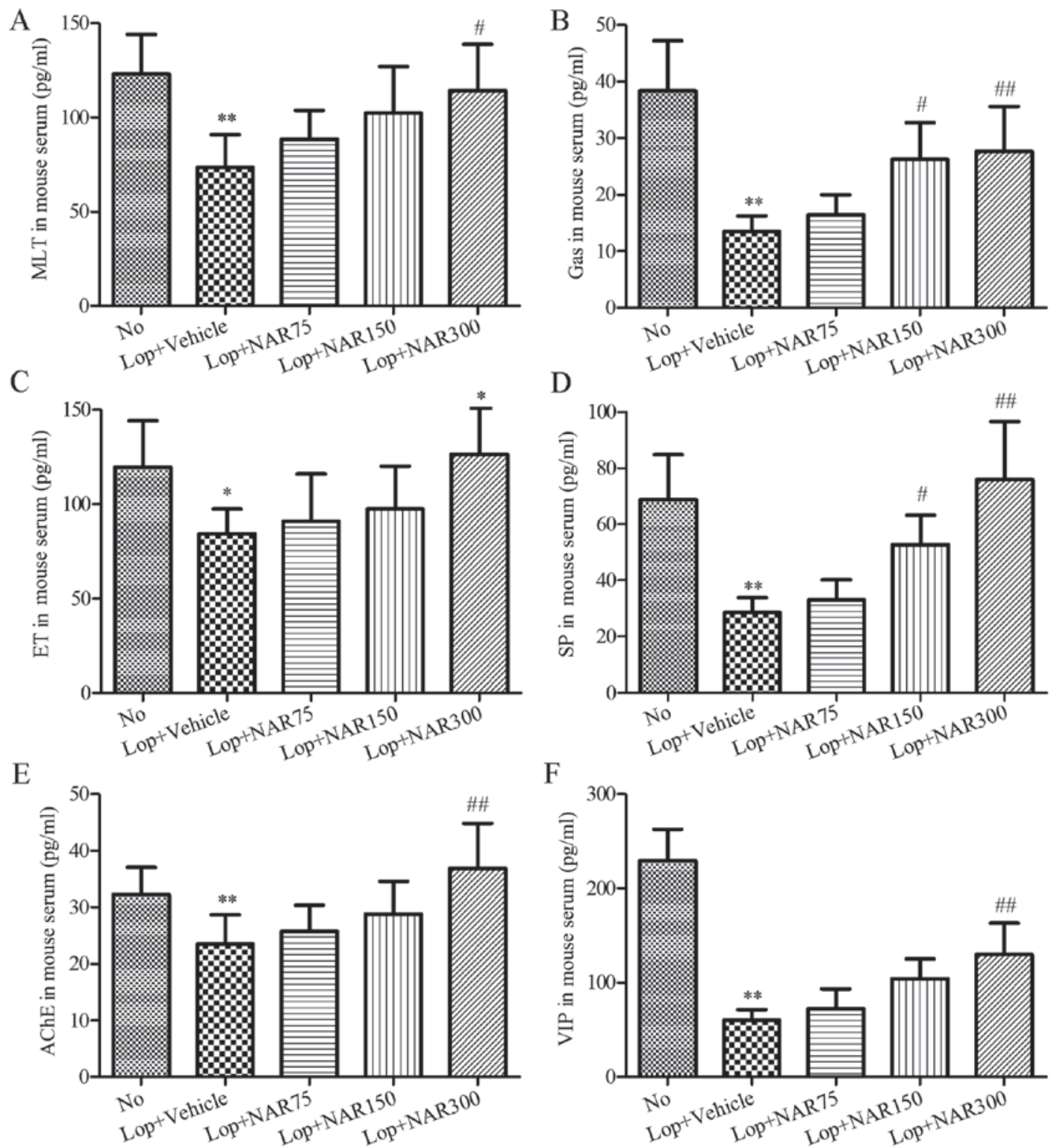

Figure 3. Effects of NAR on serum parameters in mice with Lop-induced constipation. Consitipation was induced by the intragastric administration of Lop followed by treatment with or without NAR. The serum was collected separately for the analysis of hte concentrations of (A) MTL, (B) Gas, (C) ET, (E) AChE, (D) SP and (F) VIP in mice with Lop-induced constipation by ELISA. ${ }^{* *} \mathrm{P}<0.01$ compared to the No group; ${ }^{*} \mathrm{P}<0.05$ and ${ }^{\# /} \mathrm{P}<0.01$ compared to Lop + Vehicle group. NAR, naringenin; Lop, loperamide; MTL, motilin; Gas, gastrin; AChE, acetylcholinesterase; SP, substance P; VIP, vasoactive intestinal peptide. The mouse groups were as follows: No, negative control, mice treated with saline; Lop + Vehicle, mice treated with Lop and the vehicle; Lop + NAR75, mice treated with Lop and NAR at $75 \mathrm{mg} / \mathrm{kg}$ body weight; Lop + NAR150, mice treated with Lop and NAR at $150 \mathrm{mg} / \mathrm{kg}$ body weight; Lop + NAR300, mice treated with Lop and NAR at $300 \mathrm{mg} / \mathrm{kg}$ body weight.

mechanisms of action of NAR on Lop-induced constipation in mice. The histological alterations following treatment with NAR were investigated in the colons of mice with Lop-induced constipation by H\&E staining (Fig. 4A). The mice treated with Lop alone exhibited a marked loss of epithelium of the colon, crypt damage and goblet cell depletion compared with the No group (Fig. 4A, middle panel). Following treatment with NAR, moderately destructed epithelial cells were found when compared with the Lop + Vehicle group. The colons of mice treated with $300 \mathrm{mg} / \mathrm{kg}$ NAR exhibited intact goblet cells and epithelial cells, which were comparable to those of the No group (Fig. 4A, right panel). Moreover, enteric nerverelated factors, such as TRPV1, GDNF, BDNF and NOS are important enteric nerve-related factors. The mRNA levels of these factors were detected following treatment with NAR in mice with Lop-induced constipation by RT-PCR analysis. The results revealed that NAR altered the mRNA levels of TRPV1, GDNF, BDNF and NOS. The mRNA expression levels of TRPV1 and NOS were increased by Lop administration, whereas NAR significantly decreased the mRNA levels of TRPV1 and NOS. The mRNA expression of GDNF and BDNF showed opposite trends (Fig. 4B). In addition, the protein expression levels of these enteric nerve-related factors following treatment with NAR were also examined in mice with Lop-induced constipation by western blot analysis. As shown in Fig. 4C, Lop induced a high level of TRPV1, as well 
A





D

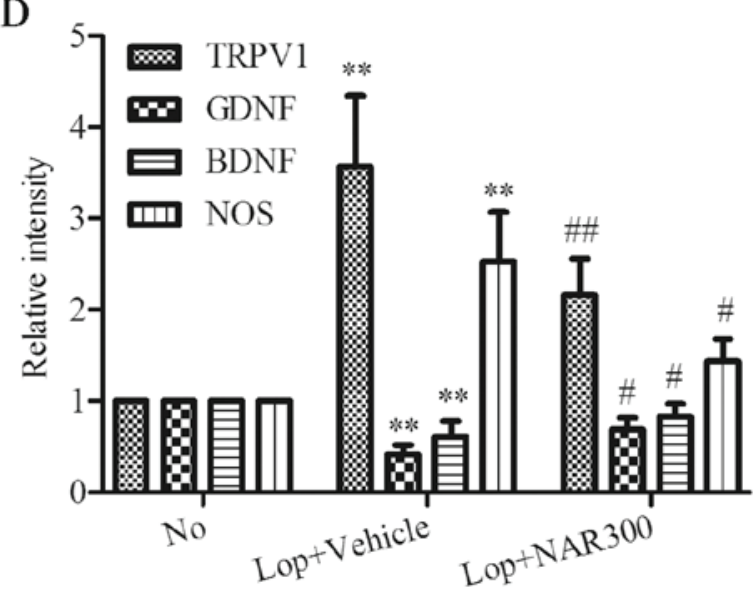

Figure 4. Histological alterations and the expression levels of enteric nerve-related factors in the colons of mice with Lop-induced constipation. (A) H\&E-stained sections of colon tissues of mice from the No, Lop + Vehicle, Lop + NAR75, Lop + NAR150 and Lop + NAR300 groups were observed using a light microscope. Scale bar, $400 \mu \mathrm{M}$. (B) NAR regulated the mRNA levels of enteric nerves-related factors in the colons of Lop-induced constipated mice. Consitipation was induced by the intragastric administration of Lop followed by treatment with or without NAR. The mRNA levels of TRPV1, GDNF, BDNF and NOS in colons of mice iwth Lop-induced constipation were analyzed by RT-PCR. (C) The expression levels of enteric nerve-related factors in the colons of mice with Lopinduced constipation. (C) The expression levels of TRPV1, GDNF, BDNF and NOS were examined by western blot analysis and the quantitative analysis of gray intensity was calculated and shown in (D). ${ }^{* *} \mathrm{P}<0.01$ compared to the No group; ${ }^{\#} \mathrm{P}<0.05$ and ${ }^{\# \#} \mathrm{P}<0.01$ compared to Lop + Vehicle group. Lop, loperamide; NAR, naringenin; TRPV1, transient receptor potential cation channel subfamily V member 1; GDNF, glial cell line-derived neurotrophic factor; BDNF, brain-derived neurotrophic factor; NOS, nitric oxide synthase. The mouse groups were as follows: No, negative control, mice treated with saline; Lop + Vehicle, mice treated with Lop and the vehicle; Lop + NAR75, mice treated with Lop and NAR at $75 \mathrm{mg} / \mathrm{kg}$ body weight; Lop + NAR150, mice treated with Lop and NAR at $150 \mathrm{mg} /$ $\mathrm{kg}$ body weight; Lop + NAR300, mice treated with Lop and NAR at $300 \mathrm{mg} / \mathrm{kg}$ body weight.

as NOS, and the downregulation of GDNF and BDNF; these effects were reversed by treatment with $300 \mathrm{mg} / \mathrm{kg}$ NAR to a great degree (Fig. 4C). The quantitative value of gray intensity analysis revealed that treatment with NAR inhibited the protein levels of TRPV1 and NOS from $3.57 \pm 0.77$ to $2.16 \pm 0.40$ and from $2.53 \pm 0.54$ to $1.43 \pm 0.25$, respectively compared with the Lop + Vehicle group. NAR also increased the levels of GDNF and BDNF from $0.42 \pm 0.10$ to $0.69 \pm 0.13$ and $0.61 \pm 0.17$ to $0.83 \pm 0.14$, respectively, compared with the Lop + Vehicle group $(\mathrm{P}<0.05$; Fig. 4D). These results revealed that NAR attenuated the disordered expression of enteric nerve-related factors in mice with Lop-induced constipation.

Effect of NAR on the expression levels of c-Kit and SCF in the colons of mice with Lop-induced constipation. ICCs have been reported to be involved in the pathogenesis of a number of gastrointestinal motility dysfunctions, including idiopathic STC (12). c-Kit is recognized to be the specific marker of ICCs with its receptor SCF that binds to it (13). In this study, to investigate the effects of NAR on ICCs, the mRNA and protein expression levels of c-Kit and SCF in colon tissues were determined by RT-PCR and western blot analysis following treatment with NAR in mice with Lop-induced constipation.
As shown in Fig. 5A, Lop induced the downregulation of both the c-Kit and SCF mRNA levels in colon tissues, whereas treatment with NAR markedly altered the mRNA levels of c-Kit and SCF $(0.61 \pm 0.17$ to $0.83 \pm 0.14)$. Identical to the RT-PCR results, western blot analysis revealed that NAR also increased the c-Kit and SCF expression levels which had been decreased by Lop, and the levels returned to levels similar to those of the No group ( $\mathrm{P}<0.05$; Fig. 5B). The quantitative value of gray intensity analysis revealed that treatment with NAR increased the c-Kit and SCF levels from $0.52 \pm 0.11$ to $0.76 \pm 0.13$ and $0.39 \pm 0.10$ to $0.61 \pm 0.13$, respectively, compared with the Lop + Vehicle group ( $\mathrm{P}<0.05$; Fig. 5C).

$N A R$ increases the production of AQP3 in the colons of mice with Lop-induced constipation. AQP3 plays an important role in regulating water transfer in the colon (40). Thus, to examine the effect of NAR on the expression of AQP3 in the colons of mice with Lop-induced constipation, the mRNA levels of AQP3 in colon tissues were determined by RT-PCR analysis following treatment with $300 \mathrm{mg} / \mathrm{kg}$ NAR. As shown in Fig. 6A, compared with the No group, Lop decreased the mRNA level of AQP3 by half (from $1.00 \pm 0.00$ to $0.51 \pm 0.13 ; \mathrm{P}<0.05)$, whereas NAR increased it 

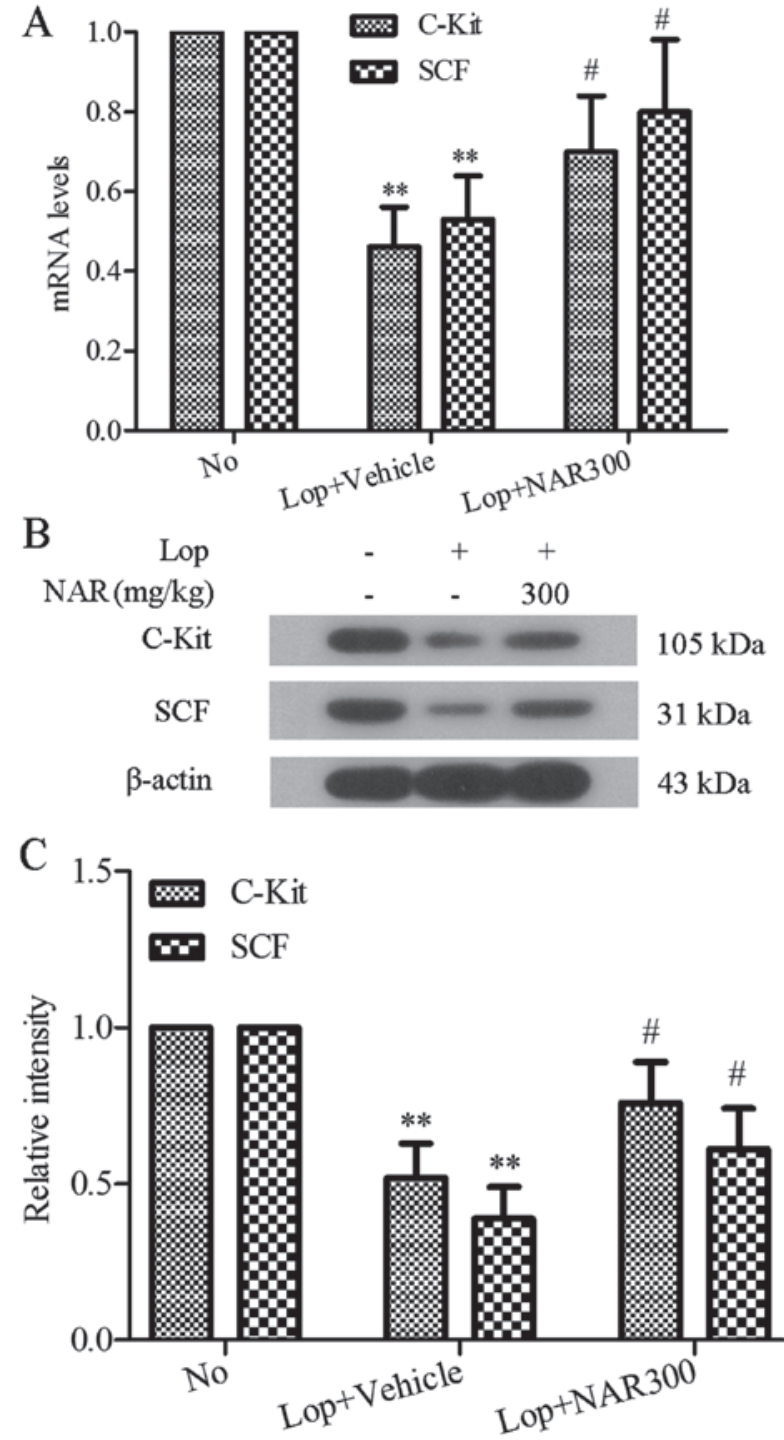

Figure 5. Effect of NAR on the expression levels of c-Kit and SCF in the colons of mice with Lop-induced constipation. (A) The mRNA levels of c-Kit and SCF in colons of mice with Lop-induced constipation were analyzed by RT-PCR. (B and C) The expression levels of c-Kit and SCF in the colons of mice with Lop-induced constipation. (B) The expression levels of c-Kit and SCF were examined by western blot analysis and the quantitative analysis of gray intensity was calculated and shown in $(C) .{ }^{* *} \mathrm{P}<0.01$ compared to the No group; ${ }^{\#} \mathrm{P}<0.05$ and ${ }^{\# \#} \mathrm{P}<0.01$ compared to Lop + Vehicle group. NAR, naringenin; Lop, loperamide; SCF, stem cell factor. The mouse groups were as follows: No, negative control, mice treated with saline; Lop + Vehicle, mice treated with Lop and the vehicle; Lop + NAR75, mice treated with Lop and NAR at $75 \mathrm{mg} / \mathrm{kg}$ body weight; Lop + NAR150, mice treated with Lop and NAR at $150 \mathrm{mg} / \mathrm{kg}$ body weight; Lop + NAR300, mice treated with Lop and $\mathrm{NAR}$ at $300 \mathrm{mg} / \mathrm{kg}$ body weight.

from $0.51 \pm 0.13$ to $0.75 \pm 0.16$ ( $\mathrm{P}<0.05$; Fig. $6 \mathrm{~A})$. Western blot analysis was the used to examine the protein levels of AQP3, which showed the same trend as the mRNA levels (Fig. 6B). The quantitative value of gray intensity analysis revealed that treatment with NAR increased the expression level of AQP3 from $0.31 \pm 0.07$ to $0.65 \pm 0.13$, compared with the Lop + Vehicle group (P<0.01; Fig. $6 \mathrm{C})$. Finally, IHC was used to observe the alterations in the levels of AQP3 following treatment with NAR in the colons of mice with Lop-induced constipation. The data indicated that AQP3 was expressed mainly in the apical and lateral mucosal epithelial cells in the colon tissues

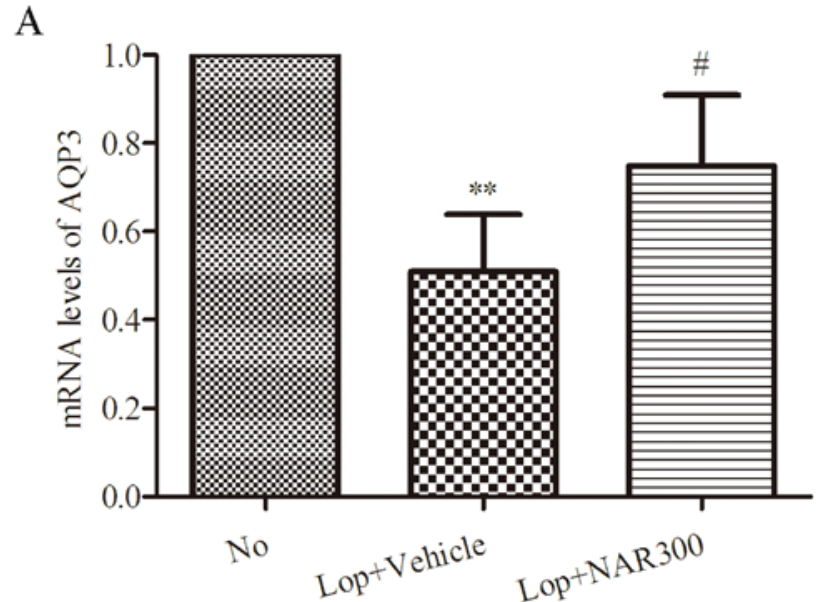

B



$\mathrm{C}$


Figure 6. NAR increases the production of AQP3 in the colons of mice with of Lop-induced constipation. (A) NAR upregulated the mRNA levels of AQP3 which were decreased by Lop in the colons of constipated mice. The mRNA level of AQP3 in colons of mice with Lop-induced constipation mice was examined by RT-PCR analysis. (B) The expression level of AQP3 in the colons of Lop-induced constipated mice. (C) The expression level of AQP3 was examined by western blot analysis and the quantitative analysis of gray intensity was calculated and shown in (C). (D) Protein expression of AQP3 in the colons of mice Lop-induced constipation detected by immunohistochemistry. Scale bar, $400 \mu \mathrm{M}$. ${ }^{* *} \mathrm{P}<0.01$ compared to the No group; ${ }^{\#} \mathrm{P}<0.05$ and ${ }^{\# \#} \mathrm{P}<0.01$ compared to Lop+Vehicle group. Lop, loperamide; NAR, naringenin; AQP3, aquaporin 3. The mouse groups were as follows: No, negative control, mice treated with saline; Lop + Vehicle, mice treated with Lop and the vehicle; Lop + NAR75, mice treated with Lop and NAR at $75 \mathrm{mg} / \mathrm{kg}$ body weight; Lop + NAR150, mice treated with Lop and NAR at $150 \mathrm{mg} / \mathrm{kg}$ body weight; Lop + NAR300, mice treated with Lop and NAR at $300 \mathrm{mg} / \mathrm{kg}$ body weight. 
of healthy mice. Lop decreased the expression of AQP3 both in the apical and lateral mucosal epithelial cells of the colon tissue of constipated mice. However, treatment with NAR attenuated this phenomenon. NAR increased the expression of AQP3 which had been decreased by Lop. These results suggest that NAR increases the expression of AQP3 in the colons of mice with Lop-induced constipation.

\section{Discussion}

Constipation is a chronic gastrointestinal disorder characterized by symptoms, such as infrequent bowel movements, difficulty during defecation and the sensation of incomplete bowel evacuation (14) that causes discomfort and affect the quality of life of patients (15). It may arise from a variety of causes, including dietary habits, psychological stress and the use of chemical compounds, such as morphine (16). NAR, as a flavonoid from citrus fruits, has been reported to exert multiple effects, including relieving constipation. However, the detailed mechanisms through which NAR exerts laxative effects remain to be elucidated. Thus, in this study, the laxative effects of NAR were evaluated in Lop-induced constipated mice. We found that NAR relieved mice iwth Lop-induced constipation based on the changes of fecal parameters (numbers, weight and water content), the intestinal charcoal transit ratio and the histological alteration. ELISA revealed that NAR regulated the production of components related to gastrointestinal metabolic in serum. The expression levels of enteric nerves-related factors, c-Kit, SCF and AQP3 were examined by western blot analysis and RT-PCR analysis, respectively. The results of this study suggest that NAR relieves Lop-induced constipation by upregulating the expression of AQP3.

Several chemical compounds, such as Lop and morphine are widely used to induce constipation in laboratory animals. Among these, Lop is well known to stimulate the extension of stool evacuation time and to delay intestinal luminal transit through the inhibition of water secretion (17), as well as smooth movement in the intestinal wall $(18,19)$. Furthermore, Lop has been used to induce constipation in a variety of studies to determine the cause of constipation and identify novel compounds with therapeutic effects $(15,20,21)$. In the present study, we used Lop to induce constipation and observed the human-like symptoms of constipation in ICR mice injected with Lop without any specific problems.

Fecal parameters including fecal numbers, weight and water contents and the intestinal charcoal transit ratio are considered to be important factors for the evaluation of constipation symptoms and the therapeutic effects of drugs. In our study, the body weight did not differ between the experimental groups, while stool-related factors, such as fecal number, weight and water contents and the intestinal charcoal transit ratio were shown to be markedly decreased in mice followng the administration of Lop. Therefore, the observations indicated that a successful model of constipation was established. However, these alterations were significantly recovered by treatment with NAR. Treatment with NAR induced an increase in fecal numbers, weight and water contents and the intestinal charcoal transit ratio in a dose-dependent manner (Figs. 1 and 2). Yang et al reported that NAR produced a laxative effect and alleviated the symptoms of Lop-induced constipation in rats (11). To the best of our knowledge, our study demonstrated for the first time that NAR exerted a laxative effect in mice with Lop-induced constipation.

On the other hand, we found that the serum levels of MTL, Gas, ET, SP, AChE and VIP in mice iwth Lop-induced constipation were lower than those in the No-treated mice. As previously reported, MTL is the intestinal hormone which is responsible for regulating the gastrointestinal motility in response to the intake of food, as well as hunger stimuli (22). It has been indicated that the mean function of MTL is to stimulate the production of pepsin and increase the migrating motor complex (MMC) of gastrointestinal motility (23). Gas has been reported to be a peptide hormone that stimulates the secretion of gastric acid $(\mathrm{HCl})$ by the parietal cells of the stomach, promotes pyloric sphincter relaxation and aids in gastric motility. It is released by $\mathrm{G}$ cells in the pyloric antrum of the stomach, duodenum and the pancreas (24). ET is a peptide that constricts blood vessels and raises blood pressure. In constipation, gastrointestinal disease occurs accompanied by not also intestinal obstruction, but also by cardio-cerebrovascular diseases in the elderly (25). In our study, Lop suppressed the release of MTL, Gas as well as ET, indicating constipation (23). However, treatment with NAR increased the production of MTL, Gas and ET in a dose-dependent manner. On the other hand, in patients with constipation, abnormal neurotransmitters have been found in the muscular layer of their intestinal walls, including the deficiency of SP, which is recognized to contribute to peristalsis (26). In the gastrointestinal tract, as is known, muscle contraction, mucus secretion, as well as myenteric nerve plexus are regulated by AChE (27). The dysfunction of the neuropeptide VIP may initiate the functional changes observed in constipation (28). In our study, we found a significant decrease in the levels of SP, AChE and VIP in the Lop + Vehicle group, whereas NAR increased these leels in a dose-dependent manner (Fig. 3). These data suggest that NAR relieves the symptoms of constipation by increasing the serum levels of MTL, Gas, ET, SP, AChE and VIP induced by Lop.

Constipation is associated with colonic abnormalities. In our study, the surface mucus thickness in the colonic lumen and the thickness of the colonic mucosa were shrunken in the Lop + Vehicle group. Treatment with NAR restored the thickness of the mucus and muscular layer compared with No group (Fig. 4A). The data indicated that histological changes were attenuated by NAR in the gastrointestinal tract of mice with Lop-induced constipation.

It has been reported that TRPV1, which is involved in the modulation and transmission of pain (nociception), as well as the integration of diverse painful stimuli, regulates bowel movements. Activated TRPV1 induces the release of the neurotransmitter, which leads to the dysfunction of gastrointestinal movement. High levels of TRPV1 expression are always found in gastrointestinal damage (29). In this study, the constipated mice had a much higher level of TRPV1, whereas NAR reduced the levels of TRPV1 (Fig. 4C and D). GDNF derived from intestinal smooth muscle cells is a key factor influencing the structural and functional development of myenteric neurons (30). The enhancement of GDNF facilitates the repair of the damaged gastrointestinal tract, which contributes to avoiding constipation (31). On the other hand, BDNF may play a critical role in intestinal motility in 
constipation. It canalter the gastrointestinal innervation structure and can lead to smooth muscle secondary degeneration (32). NOS is a key factor which produces endogenous NO that widely exists in gastrointestinal tissues and plays an important role in modulating gastrointestinal movements. The increasing level of NO has been shown to be involved in colonic motility disorders of constipation (33). The downregulation of NOS can reduce the production of $\mathrm{NO}$, which is a feasible way to relieve constipation (34). We found that NAR increased the mRNA and protein expression levels of both GDNF and BDNF in colon tissue and reduced the TRPV1 and NOS expression levels in mice with Lop-induced constipation.

ICCs have been shown to be the pacemaker cells of the intestine and have been implicated in the pathogenesis of a number of gastrointestinal motility dysfunctions, including idiopathic STC (35). A major breakthrough in this field was the discovery that the tyrosine kinase receptor, c-Kit, and its ligand, SCF, are critical in the normal development, maturation, and maintenance of the phenotype of ICCs, which can be reliably identified by c-Kit immunohistochemical techniques. The blockade of c-Kit with neutralizing antibody can induce the transdifferentiation of ICCs to a smooth muscle phenotype, and intestinal slow waves disappear (36). Several studies have indicated that the number of ICCs are decreased in the colons of patients with STC (37-39). However, the mechanisms involved are unknown. In our study, NAR significantly upregulated the levels of both c-Kit and SCF in mice with Lop-induced constipation (Fig. 5). These data thus suggested that NAR increased the numbers of ICCs in mice with Lop-induced constipation.

It is known that AQPs are primarily expressed in the mucosal epithelial cells in the colon, in which AQP3 plays a central role in water reabsorption across colonic surface cells (40). Extensive research has been conducted on AQP3. Kon et al reported that morphine increases the AQP3 expression level in the colon, which promotes water absorption from the luminal side to the vascular side and causes constipation (41). In this study, we found that NAR increased the mRNA and protein expression levels of AQP3 in the colon, as shown by western blot analysis. Furthermore, a positive correlation was observed between this increase in the AQP3 level and the increase in fecal water content (Figs. 1D and 6). In addition, NAR increased the level of AQP3 both in apical and lateral mucosal epithelial cells in the colons of mice with Lop-induced constipation. These results suggest that NAR relieves the symptoms of constipation by increasing the level of AQP3 in the colon, which is associoated with the prevention of water reabsorption from the luminal side to the vessel. However, the precise mechanisms through which NAR relieves constipation in mice with Lop-induced constipation remain to be further elucidated.

In conclusion, to the best of our knowledge, our study demonstrates for the first time that NAR relieves the symptoms of constipation, which is associated with the increased expression of ICC markers (c-Kit and SCF) and AQP3 in mice with Lop-induced constipation mice. Our results suggest the possible use of NAR in the treatment of constipation.

\section{References}

1. Bassotti $\mathrm{G}$ and Blandizzi C: Understanding and treating refractory constipation. World J Gastrointest Pharmacol Ther 5: $77-85,2014$.
2. Bassotti G: Understanding constipation treatment: do we need to strain to obtain better results? Expert Opin Drug Metab Toxicol 9: 387-389, 2013.

3. Mostafa SM, Bhandari S, Ritchie G, Gratton N and Wenstone R: Constipation and its implications in the critically ill patient. Br J Anaesth 91: 815-819, 2003.

4. Ouyang A and Locke GR 3rd: Overview of neurogastroenterology-gastrointestinal motility and functional GI disorders: classification, prevalence, and epidemiology. Gastroenterol Clin North Am 36: 485-498, 2007.

5. Wang HL: Understanding the pathogenesis of slow-transit constipation: one step forward. Dig Dis Sci 60: 2216-2218, 2015.

6. He CL, Burgart L, Wang L, Pemberton J, Young-Fadok T, Szurszewski J and Farrugia G: Decreased interstitial cell of cajal volume in patients with slow-transit constipation. Gastroenterology 118: 14-21, 2000.

7. Andromanakos NP, Pinis SI and Kostakis AI: Chronic severe constipation: current pathophysiological aspects, new diagnostic approaches, and therapeutic options. Eur J Gastroenterol Hepatol 27: 204-214, 2015.

8. Chan OT, Chiles L, Levy M, Zhai J, Yerian LM, Xu H, Xiao SY, Soffer EE, Conklin JL, Dhall D, et al: Smoothelin expression in the gastrointestinal tract: implication in colonic inertia. Appl Immunohistochem Mol Morphol 21: 452-459, 2013.

9. Renugadevi J and Prabu SM: Cadmium-induced hepatotoxicity in rats and the protective effect of naringenin. Exp Toxicol Pathol 62: 171-181, 2010.

10. Ekambaram G, Rajendran P, Magesh V and Sakthisekaran D: Naringenin reduces tumor size and weight lost in N-methyl-N'-nitro-N-nitrosoguanidine-induced gastric carcinogenesis in rats. Nutr Res 28: 106-112, 2008.

11. Yang ZH, Yu HJ, Pan A, Du JY, Ruan YC, Ko WH, Chan HC and Zhou WL: Cellular mechanisms underlying the laxative effect of flavonol naringenin on rat constipation model. PLoS One 3: e3348, 2008.

12. Yamamoto T, Watabe K, Nakahara M, Ogiyama H, Kiyohara T, Tsutsui S, Tamura S, Shinomura Y and Hayashi N: Disturbed gastrointestinal motility and decreased interstitial cells of Cajal in diabetic db/db mice. J Gastroenterol Hepatol 23: 660-667, 2008.

13. Chai Y, Huang Y, Tang H, Tu X, He J, Wang T, Zhang Q, Xiong F, Li D and Qiu Z: Role of stem cell growth factor/c-Kit in the pathogenesis of irritable bowel syndrome. Exp Ther Med 13: 1187-1193, 2017.

14. Wald A: Chronic constipation: advances in management. Neurogastroenterol Motil 19: 4-10, 2007.

15. Wintola OA, Sunmonu TO and Afolayan AJ: The effect of Aloe ferox Mill. in the treatment of loperamide-induced constipation in Wistar rats. BMC Gastroenterol 10: 95, 2010.

16. Kakino M, Tazawa S, Maruyama H, Tsuruma K, Araki Y, Shimazawa $M$ and Hara H: Laxative effects of agarwood on low-fiber diet-induced constipation in rats. BMC Complement Altern Med 10: 68, 2010.

17. Hughes S, Higgs NB and Turnberg LA: Loperamide has antisecretory activity in the human jejunum in vivo. Gut 25: 931-935, 1984.

18. Yamada K and Onoda Y: Comparison of the effects of T-1815, yohimbine and naloxone on mouse colonic propulsion. J Smooth Muscle Res 29: 47-53, 1993.

19. Sohji Y, Kawashima K and Shimizu M: [Pharmacological studies of loperamide, an anti-diarrheal agent. II. Effects on peristalsis of the small intestine and colon in guinea pigs (author's transl)] Nihon Yakurigaku Zasshi 74: 155-163, 1978 (In Japanese).

20. Lee HY, Kim JH, Jeung HW, Lee CU, Kim DS, Li B, Lee GH, Sung MS, Ha KC, Back HI, et al: Effects of Ficus carica paste on loperamide-induced constipation in rats. Food Chem Toxicol 50: 895-902, 2012

21. Kakino M, Izuta H, Ito T, Tsuruma K, Araki Y, Shimazawa M, Oyama M, Iinuma $\mathrm{M}$ and Hara $\mathrm{H}$ : Agarwood induced laxative effects via acetylcholine receptors on loperamide-induced constipation in mice. Biosci Biotechnol Biochem 74: 1550-1555, 2010.

22. Liu Y, Zhao XR, Wang R, Qiu GQ and Zhang M: Effect of Zhizhuwan on gastrointestinal peptide concentrations in plasma of diabetic gastroenteropathy with constipation patients. Zhongguo Zhong Yao Za Zhi 33: 2966-2968, 2008 (In Chinese).

23. Suo H, Zhao X, Qian Y, Li G, Liu Z, Xie J and Li J: Therapeutic effect of activated carbon-induced constipation mice with Lactobacillus fermentum Suo on treatment. Int J Mol Sci 15: 21875-21895, 2014 
24. Iijima K, Koike T, Abe Y and Shimosegawa T: Cutoff serum pepsinogen values for predicting gastric acid secretion status. Tohoku J Exp Med 232: 293-300, 2014

25. Fevang J, Ovrebø K, Myking O, Grong K and Svanes K: Role of endothelin in the circulatory changes associated with small bowel strangulation obstruction in pigs: effects of the endothelin receptor antagonist bosentan. J Surg Res 96: 224-232, 2001.

26. Yik YI, Farmer PJ, King SK, Chow CW, Hutson JM and Southwell BR: Gender differences in reduced substance P (SP) in children with slow-transit constipation. Pediatr Surg Int 27: 699-704, 2011.

27. Moriya R, Fujikawa T, Ito J, Shirakura T, Hirose H, Suzuki J, Fukuroda T, Macneil DJ and Kanatani A: Pancreatic polypeptide enhances colonic muscle contraction and fecal output through neuropeptide $\mathrm{Y} \mathrm{Y}_{4}$ receptor in mice. Eur J Pharmacol 627 258-264, 2010

28. King SK, Sutcliffe JR, Ong SY, Lee M, Koh TL, Wong SQ Farmer PJ, Peck CJ, Stanton MP, Keck J, et al: Substance P and vasoactive intestinal peptide are reduced in right transverse colon in pediatric slow-transit constipation. Neurogastroenterol Motil 22: 883-892, 2010.

29. Geppetti P and Trevisani M: Activation and sensitisation of the vanilloid receptor: role in gastrointestinal inflammation and function. Br J Pharmacol 141: 1313-1320, 2004.

30. Rodrigues DM, Li AY, Nair DG and Blennerhassett MG: Glial cell line-derived neurotrophic factor is a key neurotrophin in the postnatal enteric nervous system. Neurogastroenterol Motil 23: e44-e56, 2011.

31. Saffrey MJ: Cellular changes in the enteric nervous system during ageing. Dev Biol 382: 344-355, 2013.

32. Chen F, Yu Y, Wang P, Dong Y, Wang T, Zuo X and Li Y: Brain-derived neurotrophic factor accelerates gut motility in slow-transit constipation. Acta Physiol (Oxf) 212: 226-238, 2014

33. Peregud DI, Yakovlev AA, Stepanichev MY, Onufriev MV, Panchenko LF and Gulyaeva NV: Expression of BDNF and TrkB phosphorylation in the rat frontal cortex during morphine withdrawal are NO dependent. Cell Mol Neurobiol 36: 839-849, 2015.
34. Tomita R, Igarashi S, Fujisaki S and Tanjoh K: The effects of neurotensin in the colon of patients with slow transit constipation. Hepatogastroenterology 54: 1662-1666, 2007.

35. Xu J, Chen Y, Liu S and Hou X: Electroacupuncture regulates apoptosis/proliferation of intramuscular interstitial cells of cajal and restores colonic motility in diabetic constipation rats. Evid Based Complement Alternat Med 2013: 584179, 2013.

36. Farrugia G: Interstitial cells of Cajal in health and disease. Neurogastroenterol Motil 20: 54-63, 2008.

37. Yu CS, Kim HC, Hong HK, Chung DH, Kim HJ, Kang GH and Kim JC: Evaluation of myenteric ganglion cells and interstitial cells of Cajal in patients with chronic idiopathic constipation. Int J Colorectal Dis 17: 253-258, 2002.

38. Mostafa RM, Moustafa YM and Hamdy H: Interstitial cells of Cajal, the Maestro in health and disease. World J Gastroenterol 16: 3239-3248, 2010

39. Parthasarathy G, Chen J, Chia N, O'Connor HM, Gaskins HR and Bharucha AE: Reproducibility of assessing fecal microbiota in chronic constipation. Neurogastroenterol Motil 29: 1-10, 2017.

40. Silberstein C, Kierbel A, Amodeo G, Zotta E, Bigi F, Berkowski D and Ibarra C: Functional characterization and localization of AQP3 in the human colon. Braz J Med Biol Res 32: 1303-1313, 1999

41. Kon R, Ikarashi N, Hayakawa A, Haga Y, Fueki A, Kusunoki Y, Tajima M, Ochiai W, Machida Y and Sugiyama K: Morphine-induced constipation develops with increased aquaporin-3 expression in the colon via increased serotonin secretion. Toxicol Sci 145: 337-347, 2015.

This work is licensed under a Creative Commons Attribution-NonCommercial-NoDerivatives 4.0 International (CC BY-NC-ND 4.0) License. 